\title{
Corrosão de refratários utilizados na siderurgia. Parte IV: Caracterização de refratários post mortem
}

\section{(Corrosion of refractories used in steel metallurgy. Part IV: Characterization of post mortem refractories)}

\author{
S. R. Bragança \\ DEMAT, Universidade Federal do Rio Grande Sul, Av. Osvaldo Aranha 99/705, Porto Alegre, RS 90035-190 \\ saulorb@ufrgs.br
}

\begin{abstract}
Resumo
Neste trabalho foi realizada uma revisão dos principais aspectos encontrados na literatura especializada sobre corrosão de refratários, avaliando-se a viabilidade de determinados ensaios e relacionando-se com resultados experimentais. Refratários magnésia-carbono e doloma-carbono post mortem foram caracterizados quanto às suas propriedades microestruturais, avaliando-se essas em relação ao mecanismo de corrosão. Foram investigados os tijolos refratários utilizados como revestimento da linha de escória em uma panela de aço. A análise post mortem mostra a interface de reação entre as superfícies de corrosão e do refratário íntegro, as fases formadas, como produtos da corrosão, a perda de carbono e a infiltração de escória na matriz do refratário. Em face dessa análise, é possível se compreender o mecanismo de corrosão. Aliando-se esse conhecimento com a prática operacional, pode-se estabelecer critérios para a seleção de refratários com maior vida útil. A caracterização de um tijolo novo que apresentou recorde em sua utilização mostra as características desejáveis em um refratário.
\end{abstract}

Palavras-chave: refratários, corrosão, aciaria, microestrutura.

\begin{abstract}
In this study, the main aspects found in the literature about refractories corrosion were reviewed, evaluating the feasibility of certain tests and relating them with experimental results. The microstructural properties of magnesia-C and doloma-C post mortem refractories were characterized, evaluating them according to the corrosion mechanism. It was investigated the refractory bricks used as lining of slag line in a steel ladle. The post mortem analysis showed the surface interface of reaction between the corroded and the intact refractory, the phases formed as products of corrosion, the carbon loss and the infiltration of slag in the refractory matrix. Based on this analysis, it is possible to understand the corrosion mechanism. Combining this knowledge with up to operational practice, we can establish criteria for the selection of refractories with longer life. The characterization of a new brick that showed record in its use indicates desirable characteristics in a refractory brick.
\end{abstract}

Keywords: refractory, corrosion, steelmaking, microstructure.

\section{INTRODUÇÃO}

A relação entre as características, propriedades e corrosão de refratários é uma tarefa complexa, principalmente, devido à dificuldade de se simular em testes laboratoriais as condições que se encontram na prática industrial. $\mathrm{O}$ presente trabalho procura relacionar algumas observações encontradas na bibliografia sobre refratários utilizados na siderurgia, com as análises de refratários post mortem e a vida útil dos mesmos. Este trabalho é uma continuação de uma série de artigos publicados anteriormente sobre o tema [1-3].

Mattila et al. [4] realizaram testes de corrosão de refratários em forno rotativo, nos quais o incremento de teor de carbono de refratários $\mathrm{MgO}-\mathrm{C}$ de 5\% para 14\% propiciou o aumento à resistência à corrosão. Os autores consideraram a perda de carbono como a principal causa do desgaste de refratários $\mathrm{MgO}-\mathrm{C}$, devido à infiltração de escória, favorecendo ao choque térmico e à remoção de agregados na zona infiltrada. Para refratários de doloma, a corrosão ocorre até a saturação da escória, sendo a alumina e a sílica os principais componentes da escória de panela que infiltram no tijolo, formando compostos de baixo ponto de fusão.

Lee e Zhang [5] destacaram que em testes estacionários (teste do cadinho), a corrosão de refratários $\mathrm{MgO}-\mathrm{C}$ se dá pela formação de eutéticos de baixo ponto de fusão, sendo a dissolução do grão de $\mathrm{MgO}$ determinada pela sua solubilidade na escória. Em testes dinâmicos (rotativos) a descarbonetação e formação de camada de magnesiowustita na face quente são mais importantes.

Jansson et al. [6,7] investigaram a corrosão de refratários magnesianos e dolomíticos por meio de cilindros rotativos imersos em escórias fundidas. Eles encontraram maior desgaste com o aumento do tempo de exposição, temperatura e velocidade de rotação das amostras. Refratários com carbono apresentaram significativamente menor desgaste do que refratários sem carbono. $\mathrm{O}$ aumento de teor de $\mathrm{MgO}$ em 
refratários dolomíticos leva a uma menor corrosão, o mesmo ocorre com o aumento de teor de $\mathrm{MgO}$ na escória, sendo que os refratários puramente magnesianos foram mais resistentes que os dolomíticos. Calculando-se as energias de ativação do processo de dissolução, os autores propuseram que o passo determinante da corrosão é a transferência de massa através da camada de contorno de escória. O mecanismo de corrosão se dá pela infiltração da escória nos poros/trincas na zona descarbonetada, dissolução do refratário e dispersão dos grãos na escória.

Li et al.[8] concluíram em seu trabalho que testes em fornos de indução podem levar ao aumento da corrosão da escória e oxidação do refratário, devido a interferência do campo eletromagnético. Os autores fizeram testes comparativos em fornos de aquecimento por resistência elétrica com refratários $\mathrm{MgO}-\mathrm{C}$ de baixo teor de carbono.

Guo et al. [9] testaram refratários para produção de aço inoxidável com sistemas de vácuo (VOD e AOD) por meio de testes em cilindros rotativos. Eles concluíram ser a reação $\mathrm{MgO}+\mathrm{C}$ a principal responsável pela perda de carbono e degradação do tijolo, sendo a oxidação atmosférica e/ou redução por componentes da escória fatores secundários. Sob estas condições, não há formação de camada densa de magnésia, como no refino primário (BOF).

As diversas fontes de carbono e sua fixação na microestrutura são fundamentais ao aumento da qualidade de um refratário, destacando-se a importância das fontes particuladas e métodos de grafitização de ligantes orgânicos $[10,11]$.

O uso de antioxidantes tem mostrado ser uma forma efetiva de se prolongar a permanência do carbono na microestrutura. Os mais utilizados e estudados são os pós metálicos de $\mathrm{Al} \mathrm{e} \mathrm{Si,} \mathrm{seguidos} \mathrm{dos} \mathrm{carbetos} \mathrm{e} \mathrm{dos} \mathrm{nitretos} \mathrm{[12-}$ 14]. Outros aditivos vêm sendo testados, como nanofolhas de óxido-grafite [15] e grafite expandido [16], obtendo-se um aumento na tenacidade à fratura e resistência ao choque térmico.

$\mathrm{Na}$ literatura há o consenso que após a penetração da escória, a corrosão ocorre na parte mais fraca da microestrutura, ou seja, na fase ligante mais porosa e constituída de partículas mais finas - a matriz [5, 17].

Brosnan [17] propõe três estágios para explicar a corrosão. No estágio I, a corrosão ocorre na superfície imediata da face quente, com uma penetração $<0,1 \mathrm{~mm}$ pela escória. Se a temperatura é mantida abaixo da temperatura em que os produtos da corrosão ficam líquidos, a corrosão será muito lenta ou insignificante. O início da corrosão ocorre pelo estágio I, mas é no estágio II que ocorre ampla penetração de escória, rompimento parcial na face quente entre agregados e matriz, de modo que as partículas são erodidas imiscuindose na escória. A penetração é auxiliada pela sucção capilar, em que poros < $10 \mu \mathrm{m}$ arrastam o líquido para dentro do tijolo, atingindo até $2 \mathrm{~mm}$ da espessura do mesmo. A zona impregnada de escória apresenta uma expansão térmica diferente da zona sã, o que pode levar a ruptura em ciclos térmicos (chamado 'quebra por densificação'), recomeça-se assim o ciclo de corrosão (estágio I e estágio II). Em caso de taxas relativamente lentas de corrosão e quando a quebra por densificação não ocorrer, ou mesmo próximo ao final da vida útil do revestimento, a corrosão chega ao estágio III. Neste, a escória parece ser a única fase, provavelmente em consequência da elevada viscosidade da mesma em consequência da dissolução do refratário, mas ainda aparece alguma coerência entre os componentes da microestrutura. No entanto, a ligação na região da face quente é mínima, atingindo-se forte degradação cerca de 2 a $4 \mathrm{~mm}$ atrás da superfície.

Lee e Zhang [18] afirmam que os primeiros componentes do sólido a se dissolverem são aqueles de maior solubilidade, como partículas pequenas de menor raio de curvatura e protuberâncias de formato angular. Eles possuem maior taxa de dissolução devido à maior área superficial específica. $\mathrm{O}$ refratário após sofrer dissolução em consequência da corrosão, apresenta o arredondamento de suas partículas, como ilustra a Fig. 1.

Na prática industrial foi constato que um refratário novo que possui partículas e agregados de formato mais esférico, apresentou um desempenho muito superior em relação a outro com partículas angulares [19]. A microestrutura desses refratários é mostrada na Fig. 2, na qual se observa partículas muito mais protuberantes no produto $\mathrm{A}$, em relação ao $\mathrm{B}$. Este refino da microestrutura mostrado no produto B, com uma melhor dispersão de tamanhos de partículas, contribui ao aumento da tenacidade à fratura e da resistência ao choque térmico, além de propiciar uma maior resistência à dissolução dos agregados, em consequência de sua menor área superficial.

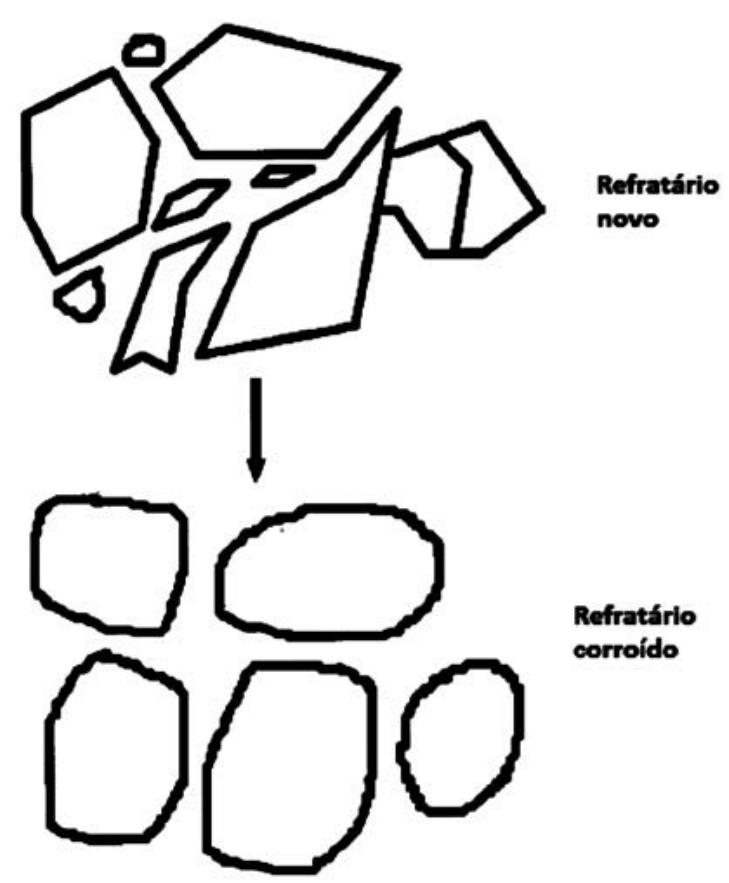

Figura 1: Arredondamento das partículas angulares após corrosão [18].

[Figure 1: Rounding of angular particles after corrosion]. 

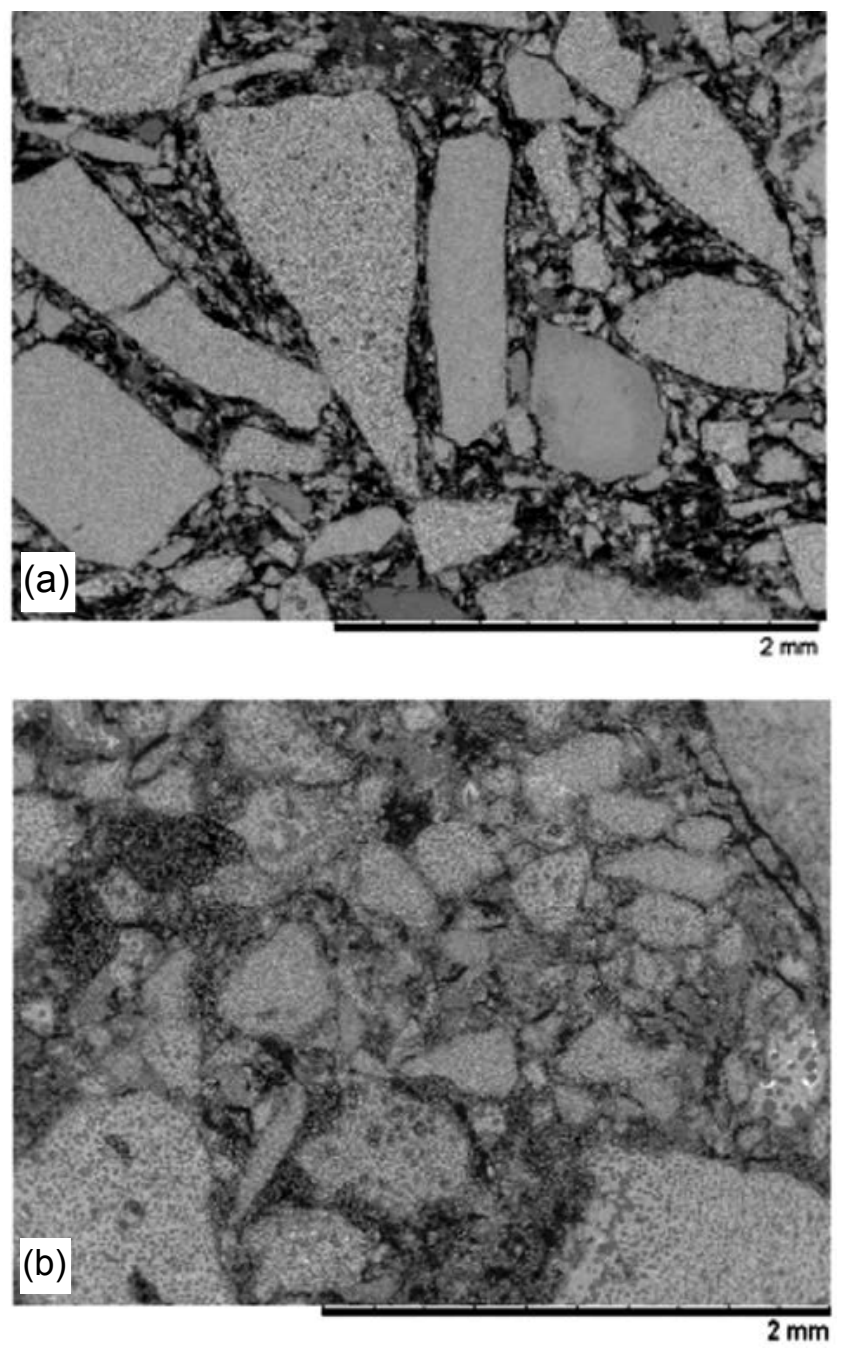

Figura 2: Micrografias obtidas em microscópio eletrônico de varredura de refratários doloma-C, mostrando partículas angulares (A) e arredondadas (B) [19].

[Figure 2: SEM micrographs of doloma-C refractories, showing angular $(A)$ and rounded $(B)$ particles.]

A formação de espinélio in situ, provou ser um meio efetivo de se aumentar a ligação cerâmica e a resistência à corrosão, devido ao desenvolvimento de uma matriz espinelizada [20]. A formação dessa matriz é mostrada na Fig. 3.

\section{MATERIAIS E MÉTODOS}

Os materiais refratários analisados neste trabalho são os tijolos post mortem (após o uso) de magnésia-carbono e doloma-carbono, utilizados em panelas para o refino de aço. Analisou-se também um refratário dolomítico novo. Eles podem ser descritos como tijolos constituídos por magnésia/ doloma sinterizada e grãos eletrofundidos, teor de carbono de $\sim 10 \%$, agentes antioxidantes, ligados a piche e curados e/ou resinados e curados. Estes refratários são utilizados em diferentes aciarias, priorizando aqui a avaliação dos refratários utilizados para os tipos aço de maior quantidade de produção.
A análise por microscopia foi realizada no microscópio eletrônico de varredura - MEV (Hitachi, TM3000). Para essa análise, as amostras foram colocadas sobre um suporte de alumínio previamente preparado com uma fita adesiva de carbono. As amostras foram obtidas por corte a seco e o polimento foi igualmente realizado a seco, com lixas de grana crescente (de 100 a 1200), sendo as amostras mantidas em dessecador a vácuo. Este cuidado é fundamental principalmente para as amostras de doloma-C.

\section{RESULTADOS E DISCUSSÃO}

\section{Caracterização dos refratários post mortem}

As Figs. 4A e B mostram aspectos relevantes sobre a corrosão de um refratário. Na interface de corrosão, encontrase uma zona onde predomina a escória e outra o refratário. Neste, ocorre a penetração de escória, dissolvendo inicialmente a matriz: a Fig. 4B mostra um agregado envolvido pela escória. Na fase escória, encontram-se agregados que foram removidos do refratário. Este mecanismo está de acordo com o modelo proposto na literatura de degradação de refratários: oxidação do carbono, aumento da molhagem do refratário pela escória, penetração na porosidade (e capilaridade), dissolução das fases mais finas (matriz), enfraquecimento da ligação entre matriz e agregados e remoção destes $[4,5,17]$.

A penetração de escória e frente de corrosão do refratário pode ser representada esquematicamente, como proposto no trabalho de Lee e Zhang [5], apresentado na Fig. 5. Esta mostra que a análise de um refratário que sofre forte degradação durante sua vida útil, em geral perdendo mais que metade de sua espessura inicial, pode ser feita, dividindose o mesmo em camadas limítrofes ou regiões de ataque. A caracterização da zona alterada pode explicar o mecanismo de reação, mostrando a presença de espécies de rápida difusão como $\mathrm{Mn}, \mathrm{Fe}$ e $\mathrm{Ca}$, formando novas fases, distintas das fases

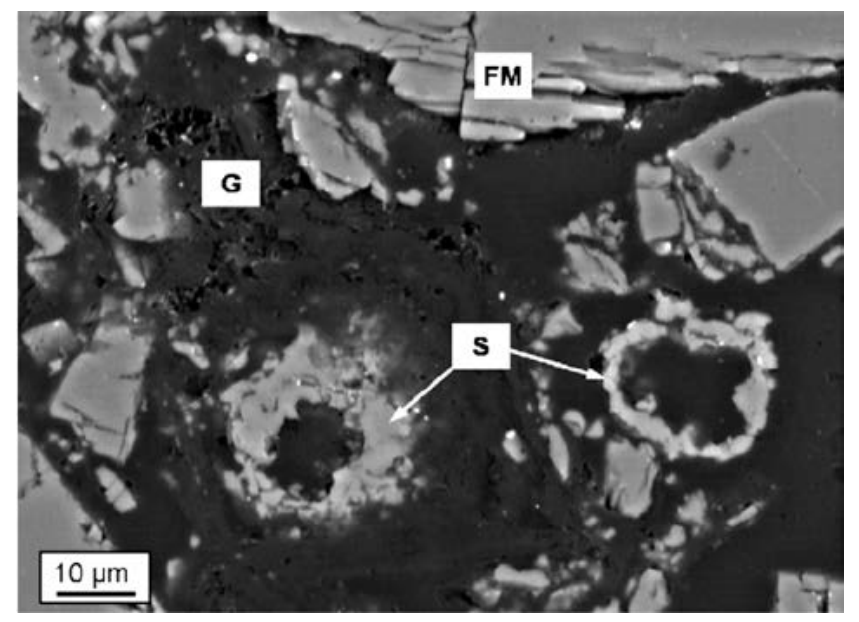

Figura 3: Micrografias obtidas em microscópio eletrônico de varredura mostrando a formação de coroa de espinélio (S) ao redor de um sítio de Al. Magnésia fundida (FM) e grafite (G) [20]. [Figure 3: SEM micrographs showing the formation of spinel shell at Al original site. Fused magnesia $(F M)$; graphite $(G)$, and spinel $(S)]$. 


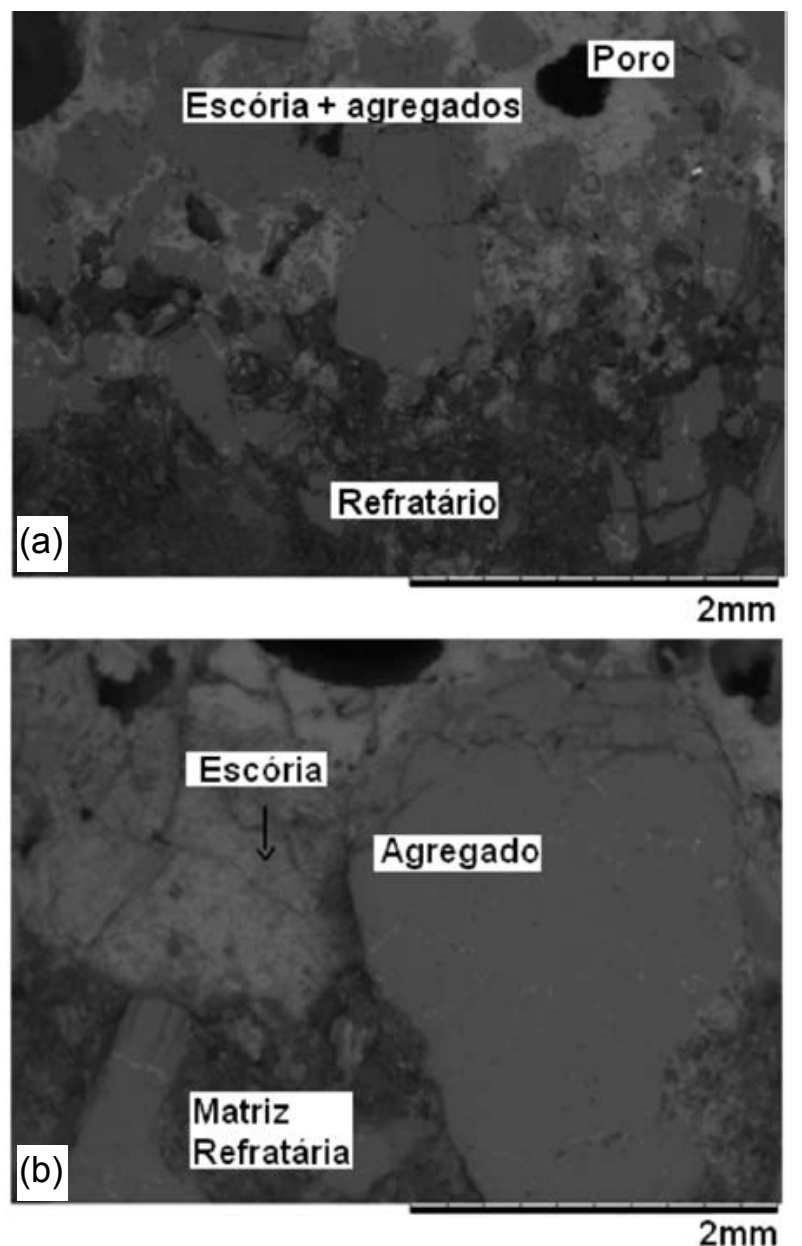

Figura 4: Micrografias obtidas em microscópio eletrônico de varredura de refratário $\mathrm{MgO}-\mathrm{C}$. Frente de corrosão. Observam-se agregados dentro da zona de escória e a dissolução preferencial da matriz.

[Figure 4: SEM micrographs of $\mathrm{MgO}-\mathrm{C}$ refractory. Slag attack. Aggegates in slag area and matrix preferential dissolution are observed.]

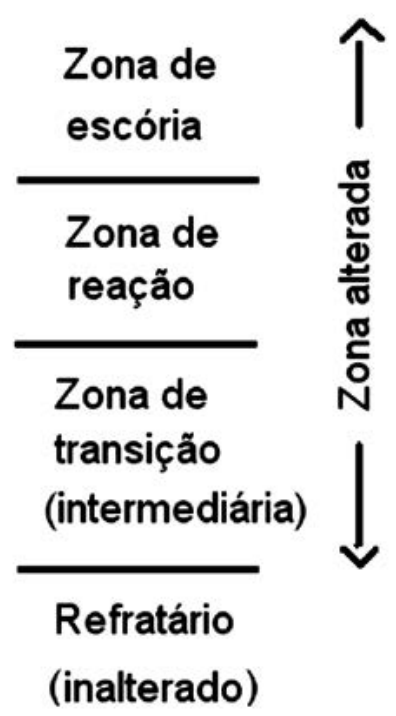

Figura 5: Várias regiões em um refratário corroído. Adaptado [5]. [Figure 5: Various zones in corroded refractory.] presentes no refratário inalterado [5]. De acordo com as denominações na Fig. 5, parte do refratário se mantém sem sofrer reação, sendo responsável pela resistência estrutural do revestimento, já que a matriz ainda possui a capacidade de ligação das partículas. As Figs. 4A e B mostram, em suas partes inferiores, o refratário relativamente íntegro.

A análise em MEV/EDS é apresentada na Fig. 6 e Tabela I. Os pontos 1 e 2 mostram baixos teores de carbono e teores mais elevados de $\mathrm{Ca}$ e Al. Por ser uma zona de escória, poder-se-ia esperar maiores teores de $\mathrm{Si}$, mas em uma análise pontual, este componente de escória pode variar bastante. No ponto 3 e área 7, observa-se que a composição do agregado varia muito pouco em relação à de um tijolo novo. As áreas 4 e 5 mostram um teor significativo de carbono. Assim, a análise química em EDS identifica as seguintes regiões:

- Pontos 1 e 2: Escória

- Ponto 3 e área 7: Agregado.

- Áreas 4 e 5: pouca alteração

- Área 6: zona de transição

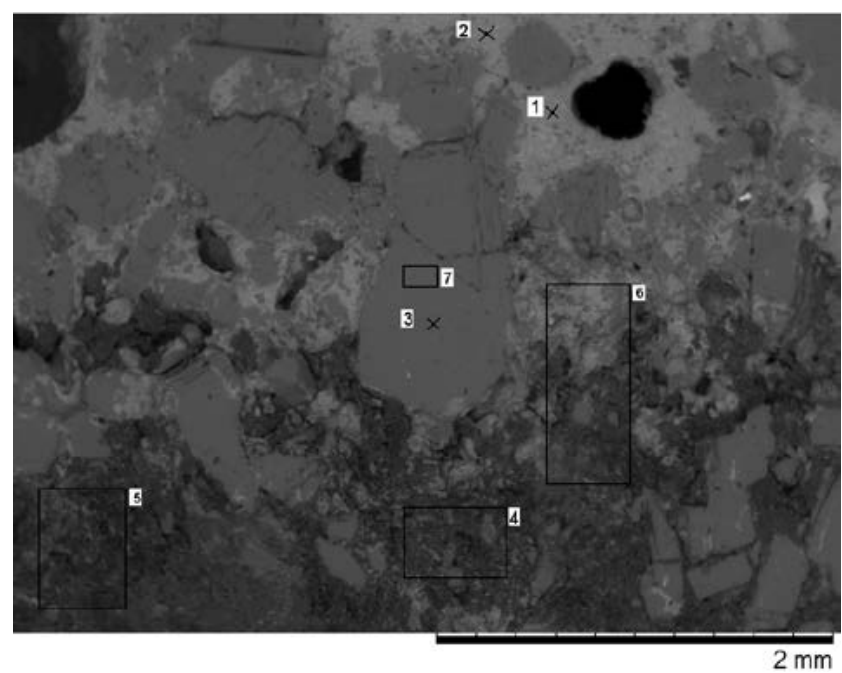

Figura 6: Micrografias obtidas em microscópio eletrônico de varredura e EDS de refratário MgO-C. Tijolo corroído de linha de escória (análises das áreas na Tabela I).

[Figure 6: SEM micrographs and EDS of $\mathrm{MgO}-\mathrm{C}$ refractory. Corroded slag line brick (analysis of spotted areas in Table I)].

É interessante notar na Tabela I que enquanto o agregado permanece relativamente inalterado (Ponto 3 e área 7), a matriz apresenta maior contaminação (áreas 4 e 5), possivelmente pela penetração de vapores e mesmo de líquido na capilaridade. A área 6 mostra exatamente uma zona de transição, com uma composição intermediária, entre a escória e a matriz.

Como se pode observar nas Figs. 4 e 6 , a resistência à infiltração da escória no tijolo é principalmente devido à presença das partículas maiores e agregados de magnésia. Como dito anteriormente, a infiltração da escória se dá preferencialmente pela matriz de carbono devido ao alto ponto de fusão do grão de periclásio. Portanto, os agregados criam uma "frente" de resistência à penetração. Assim, a qualidade, quantidade, distribuição de tamanho e, principalmente, o empacotamento, criando uma rede de contato mútuo, a qual 
Tabela I - Análise EDS de acordo com os pontos e áreas indicados na Fig. 6. Tijolo MgO-C corroído de linha de escória.

[Table I - EDS analysis of spotted areas in Fig. 6. MgO-C corroded slag line brick.]

\begin{tabular}{|c|c|c|c|c|c|c|c|}
\hline Elementos $(\%)$ & Ponto 1 & Ponto 2 & Ponto 3 & Área 4 & Área 5 & Área 6 & Área 7 \\
\hline $\mathrm{Mg}$ & 5,5 & 6,3 & 44,0 & 8,0 & 5,51 & 11,24 & 44,67 \\
\hline $\mathrm{O}$ & 45,4 & 45,3 & 42,6 & 32,5 & 28,81 & 43,66 & 43,77 \\
\hline $\mathrm{C}$ & 7,0 & 6,9 & 11,4 & 49,2 & 57,37 & 27,59 & 7,81 \\
\hline $\mathrm{Al}$ & 14,5 & 14,8 & & 0,6 & 0,45 & 3,31 & \\
\hline $\mathrm{Si}$ & 1,2 & 1,3 & & 0,4 & 0,38 & 1,03 & \\
\hline $\mathrm{Ca}$ & 22,4 & 21,0 & 0,5 & 3,6 & 3,34 & 8,27 & 0,99 \\
\hline $\mathrm{Fe}$ & 0,5 & 0,5 & 0,3 & 0,6 & 0,52 & 1,07 & 0,33 \\
\hline Outros & Ti 3,5 & $\begin{array}{l}\text { Ti } 1,5 \\
\text { F } 2,6\end{array}$ & Br 1,2 & $\begin{array}{l}\text { S } 2,2 \\
\text { K } 2,9\end{array}$ & $\begin{array}{l}\text { S } 1,8 \\
\text { K } 1,8\end{array}$ & $\begin{array}{l}\text { Ti } 0,5 \\
\text { S } 2,0 \\
\text { K } 1,3\end{array}$ & $\operatorname{Br} 2,4$ \\
\hline
\end{tabular}

deve dificultar a remoção dos mesmos, são fatores primordiais à resistência à corrosão.

A Fig. 7 mostra a infiltração de escória na microestrutura, de modo a contornar as partículas/agregados. Pode-se atribuir estas infiltrações às microtrincas formadas na face quente, além da dissolução da matriz. Portanto, a corrosão pode estar associada também às tensões térmicas. Não se pode precisar se as trincas mostradas na Fig. 7 estavam presentes durante a operação ou se formaram no resfriamento. Entretanto, sabe-se que panelas de aço são submetidas a ciclos térmicos, inclusive com o resfriamento à temperatura ambiente, para troca de peças refratárias (plugue, sede de válvula ou plugue, etc) ou reparos específicos. Analisando-se a composição química via EDS destas infiltrações, observa-se que a composição química das mesmas é similar à das escórias

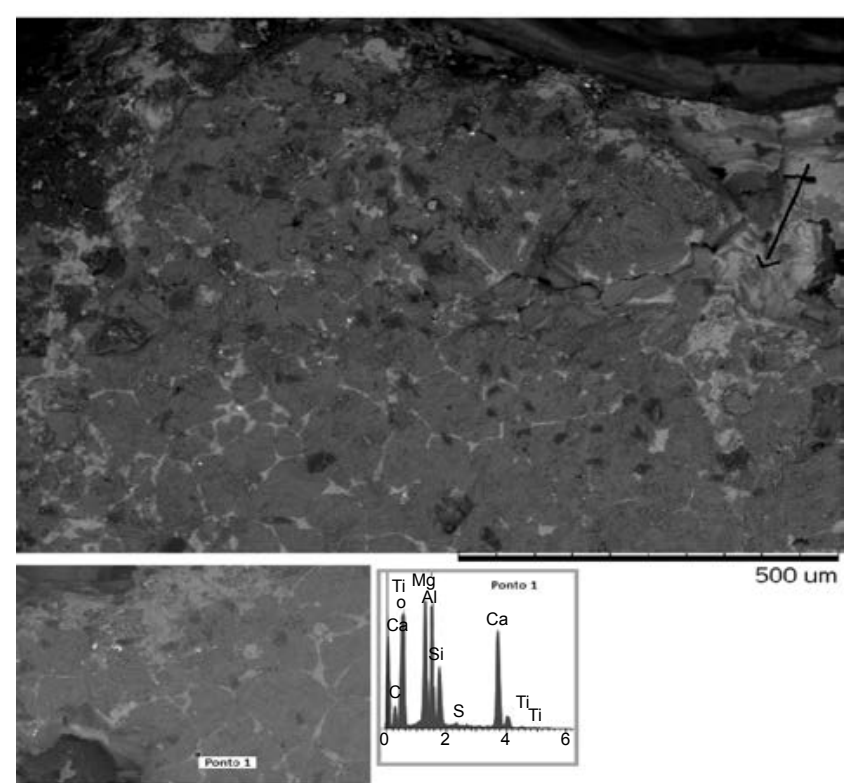

Figura 7: Micrografias obtidas em microscópio eletrônico de varredura e EDS de refratário MgO-C, mostrando infiltração da escória a partir da face quente do tijolo.

[Figure 7: SEM micrographs and EDS of MgO-C refractory, showing slag infiltration from brick hot face].

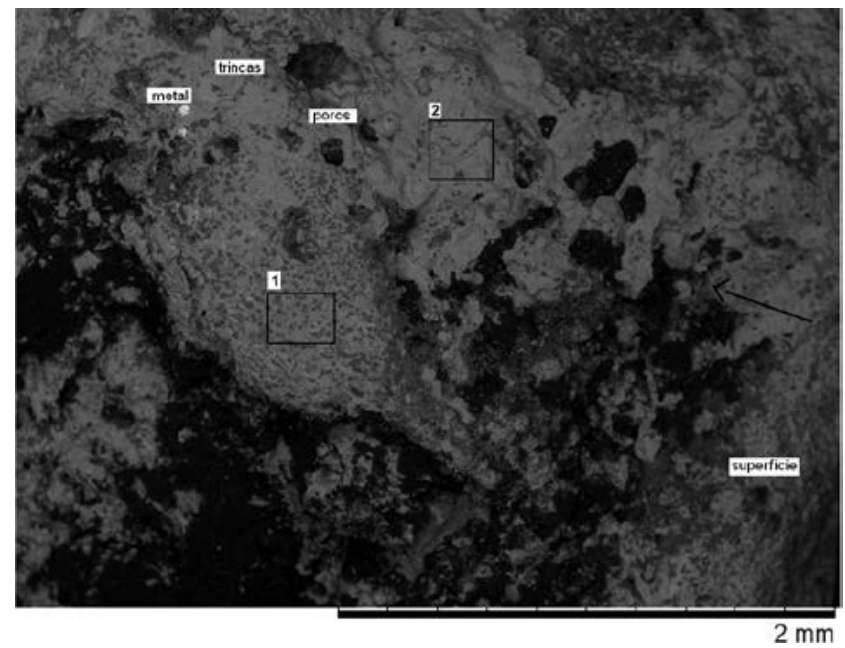

Figura 8: Micrografias obtidas em microscópio eletrônico de varredura e EDS de refratário doloma-C, mostrando infiltração da escória a partir da face quente do tijolo ("superfície"). Análise das áreas 1 e 2 na Tabela II.

[Figure 8: SEM micrographs and EDS of doloma-C refractories, showing slag infiltration from brick hot face. Analysis of areas 1 and 2 in Table II].

Tabela II - Análise EDS de acordo com as áreas indicadas na Fig. 8. Tijolo doloma-C corroído de linha de escória. [Table II - EDS analysis of spotted areas in Fig. 8. Doloma-C corroded slag line brick].

\begin{tabular}{ccc}
\hline Elementos (\%) & Área 1 & Área 2 \\
\hline $\mathrm{C}$ & 5,7 & 5,6 \\
$\mathrm{O}$ & 39,5 & 42,6 \\
$\mathrm{Mg}$ & 3,3 & 14,9 \\
$\mathrm{Al}$ & 2,2 & 2,0 \\
$\mathrm{Si}$ & 7,1 & 1,6 \\
$\mathrm{Ca}$ & 40,8 & 33,2 \\
$\mathrm{Fe}$ & 0,2 & \\
Outros & $\mathrm{I}$ & $\mathrm{S}$ \\
& 1,2 & 0,4 \\
\hline
\end{tabular}


utilizadas no refino secundário.

Na Fig. 8 observa-se que a corrosão em um refratário doloma-C repete o padrão mostrado pelo refratário $\mathrm{MgO}-\mathrm{C}$ (Fig. 7). A análise da área 1 (Fig. 8) é característica de uma região onde predomina a composição de partículas de doloma, mas com baixo teor de carbono. $\mathrm{Na}$ área 2, há igualmente pouco carbono, no entanto, a composição assemelha-se à da escória (Tabela II). Em toda a microestrutura não foi encontrada uma área que represente a composição da camada protetora (coating) tipicamente de silicato dicálcico (C2S), como referido em [2]. Isto pode ser explicado pela perda da ligação entre o $\mathrm{C} 2 \mathrm{~S}$ e a superfície do refratário, pela expansão por umidade e/ou pela reação de inversão cristalográfica do C2S, cuja variação dimensional reduz a pó o C2S [21, 22], o qual se desprende da panela, podendo-se observar esse efeito na prática industrial.

\section{Caracterização de um refratário novo}

A Fig. 9 mostra a microestrutura de um refratário doloma-C que bateu recorde de vida útil em operação, em
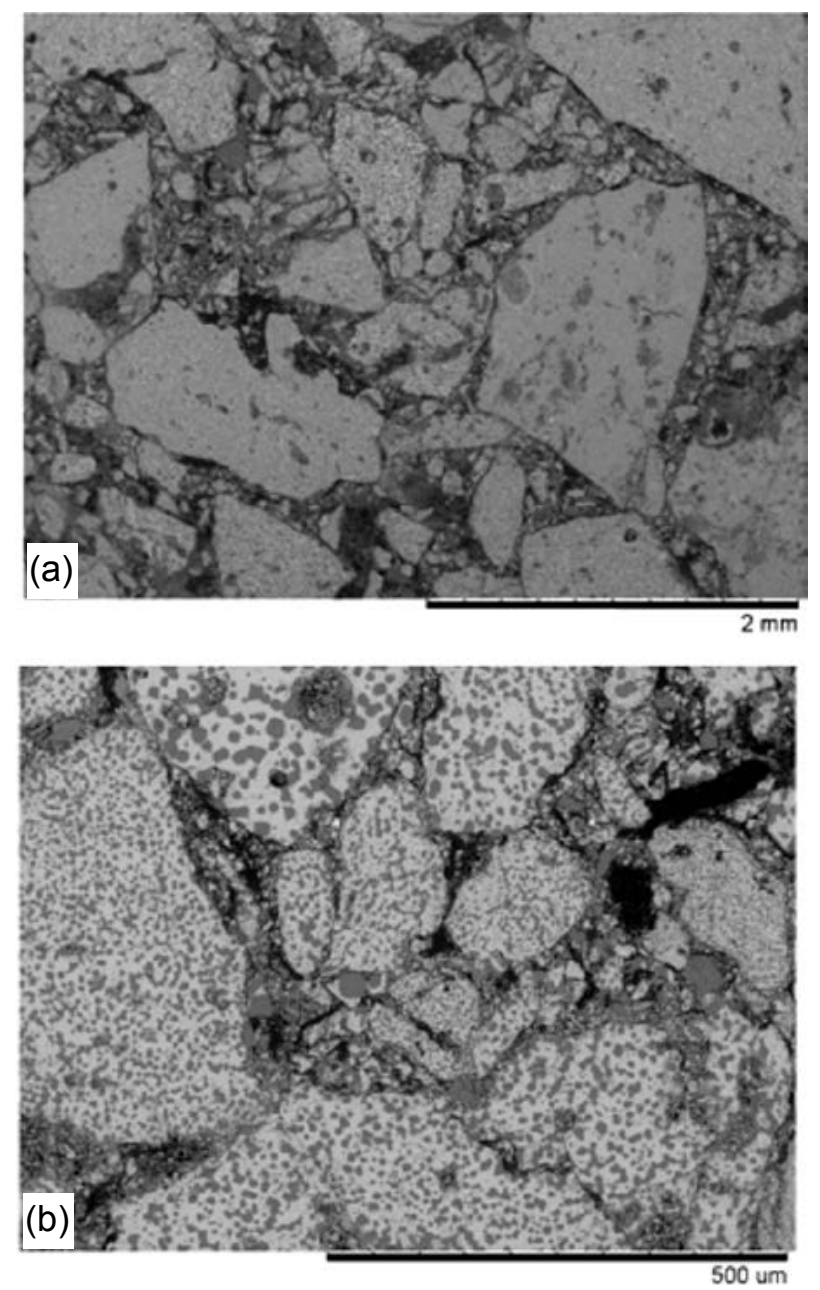

Figura 9: Micrografias obtidas em microscópio eletrônico de varredura refratário doloma-C novo. A: bom empacotamento de partículas; B: partículas arredondadas.

[Figure 9: SEM micrographs of doloma-C new refractory. A: good particle packing; $b$ : rounded particles.] aciaria. Observa-se um bom empacotamento das partículas (preenchimento da microestrutura), resultante de uma prensagem eficiente, com a distribuição das cargas de compactação em diversos pontos das partículas (Fig. 9A). De um modo geral, as partículas e agregados apresentam formato arredondados (Fig. 9B).

A Fig. 10 apresenta a análise química via EDS da microestrutura do referido tijolo (Fig. 9A). Destaca-se novamente uma boa distribuição de tamanhos e formato arredondado das partículas e, em detalhe, o contorno das partículas. A análise por microssonda mostra uma excelente pureza dos constituintes. Observa-se na Tabela III praticamente a ausência de elementos contaminantes como $\mathrm{Si}$, Al e metais alcalinos, o que comprova a qualidade e pureza deste tijolo.

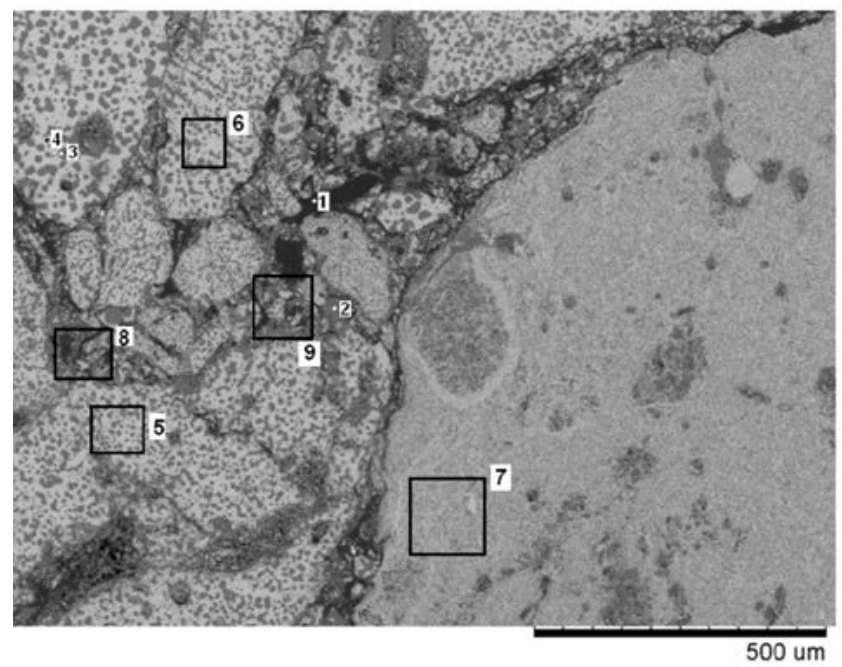

Figura 10: Micrografias obtidas em microscópio eletrônico de varredura e EDS refratário doloma-C. Pontos e áreas relacionados à Tabela III.

[Figure 10: SEM micrographs and EDS of doloma-C refractory. Analysis of points and areas in Table III].

Tabela III - Análises EDS dos pontos e áreas indicadas Fig. 10. Tijolo refratário doloma-C novo.

[Table III - EDS analysis of spotted areas in Fig. 10. Doloma-C new refractory brick.]

\begin{tabular}{cccccccccc}
\hline $\begin{array}{c}\text { Elementos } \\
(\%)\end{array}$ & 1 & 2 & 3 & 4 & 5 & 6 & 7 & 8 & 9 \\
\hline $\mathrm{C}$ & 82,1 & 15,7 & 8,1 & 6,4 & 7,6 & 7,2 & 6,5 & 34,9 & 36,7 \\
$\mathrm{O}$ & 10,9 & 40,5 & 43,5 & 39,1 & 42,2 & 42,1 & 41,7 & 32,8 & 31,4 \\
$\mathrm{Ca}$ & 4,5 & 6,1 & 8,2 & 46,9 & 32,0 & 30,7 & 33,1 & 19,2 & 19,5 \\
$\mathrm{Mg}$ & 2,3 & 37,1 & 40,0 & 6,3 & 17,8 & 19,5 & 18,4 & 12,1 & 12,0 \\
$\mathrm{Si}$ & 0,1 & 0,2 & 0,2 & 0,2 & 0,5 & 0,5 & 0,3 & 0,9 & 0,3 \\
\hline
\end{tabular}

\section{CONCLUSÕES}

A análise do refratário post mortem não resolve plenamente a complexidade da seleção das diversas propriedades que se pode optar na fabricação/aquisição de 
um refratário, a fim de se aumentar o desempenho do mesmo. No entanto, é possível se obter importantes subsídios para se determinar a escolha mais adequada a uma determinada usina. O mecanismo de corrosão mostra a infiltração de escória, a dissolução das menores partículas e remoção dos agregados. Nota-se que estes formam uma barreira à penetração, a qual é a chave a excelência na resistência à corrosão. Igualmente, é elementar se retardar a oxidação do carbono, para minimizar a molhagem do refratário. Assim, o uso de aditivos e sua eficiência podem ser comprovados pela análise microestrutural. O mesmo pode-se dizer da importância da pureza das partículas, de modo a diminuir a dissolução. Essencialmente, deve-se priorizar a otimização da distribuição de tamanho de partículas e do empacotamento das mesmas, juntamente com uma prensagem eficiente, a fim de se criar uma rede de contatos, aumentando-se a resistência à remoção dos agregados. De acordo com as informações encontradas na bibliografia e com a análise da microestrutura mostrada no presente trabalho, é difícil impedir a penetração da escória nos tijolos, de modo que a resistência à corrosão vai depender principalmente da resistência à dissolução, que por sua vez depende da pureza dos grãos, da área superficial e das propriedades da escória. Para usinas que não possuem análises on line da qualidade da escória, casos em que a escória saia da condição de saturação e em sistemas que usam vácuo $(\mathrm{AOD})$ com forte agitação, há a tendência de ocorrer a dissolução das interfaces sólidas que se formam entre refratário e escória. Por conseguinte, o aprimoramento do refratário via redução da capilaridade, meios de se manter o carbono e aditivos (como os espinélios em escala nanométrica), tornam-se os fatores mais importantes, para o aumento da vida útil do refratário.

\section{REFERÊNCIAS}

[1] S. Bragança, Cerâmica 58, 347 (2012) 280-285.

[2] S. Bragança, Cerâmica 58, 348 (2012) 459-464.

[3] S. Bragança, Cerâmica 59, 349 (2013) 39-46.

[4] R. Mattila, J. Vatanen, J. Harkki, Scandinavian J. Metallurgy 31 (2002) 241-245.

[5] W. E. Lee, S. Zhang, VII Int. Conf. Molten Slags,
Fluxes and Salts, The South African Institute of Mining and Metallurgy (2004).

[6] S. Jansson, V. Brabie,P. Jönsson, Ironmaking Steelmaking 3, 4 (2005) 283-292.

[7] S. Jansson, V.Brabie, P. Jönsson, Ironmaking Steelmaking 5, 2 (2008) 99-107.

[8] X. Li, B. Zhu, T. Wang, Ceram. Int. 38 (2012) $2105-$ 2109.

[9] M. Guo, S. Parada, P. T. Jones, J. Van Dyck, E. Boydens, D. Durinck, B. Blanpain, P. Wollants, Ceram. Int. 33 (2007) 1007-1018.

[10] C. S. Bitencourt, V. C. Pandolfelli, Cerâmica 59, 349 (2013) 84-114.

[11] C. S. Bitencourt, V. C. Pandolfelli, Cerâmica 59, 349 (2013) 1-26.

[12] A. P. Luz, V. C. Pandolfelli, Cerâmica 53, 328 (2007) 334-344.

[13] S. K. Sadrnezhaad, Z. A. Nemati, S. Mahshid, S. Hosseini, B. Hashemi J. Am. Ceram. Soc. 90, 2 (2007) 509515.

[14] S. K. Sadrnezhaad, S. Mahshid, B. Hashemi, and Z. A. Nemati, J. Am. Ceram. Soc. 89, 4 (2006) 1308-1316.

[15] T. Zhu, Y. Lin, M. Luo, S. Sang, Q. Wang, L. Zhao, Y. Li, S. Li, Ceram. Int. 39, 3 (2013) 3017-3025.

[16] T. Zhu, Y. Lin, M. Luo, S. Sang, Q. Wang, L. Zhao, Y. Li, S. Li, Ceram. Int. 39, 4 (2013) 4529-4537.

[17]D.A. Brosnan, Corrosion of refractories, In: Refractories Handbook, Ed. C. A. Schatcht, Marcel Dekker Inc., New York, EUA (2004) 39.

[18] W. E. Lee, S. Zhang, Int. Mater. Rev. 44, 3 (1999) 77 104.

[19] L. R. Marques, Avaliação técnica e microestrutural entre tijolos dolomíticos de alto desempenho para a indústria siderúrgica, Diss. Mestrado, UFRGS, RS (2012).

[20] M. Bavand-Vandchali,F. Golestani-Fard,H. Sarpoolaky, H. R. Rezaie, C. G. Aneziris, J. Eur. Ceram. Soc. 28 (2008) 563-569.

[21] A. M. Segadães, Refractários, Universidade de Aveiro, Portugal (1997) 182.

[22] A. O. Figueredo Jr, W. Q. Cassete, J. M. Nunes, Refractories Applications News 7, 5 (2002) 21-25.

(Rec. 17/10/2013, Ac. 25/01/2014) 